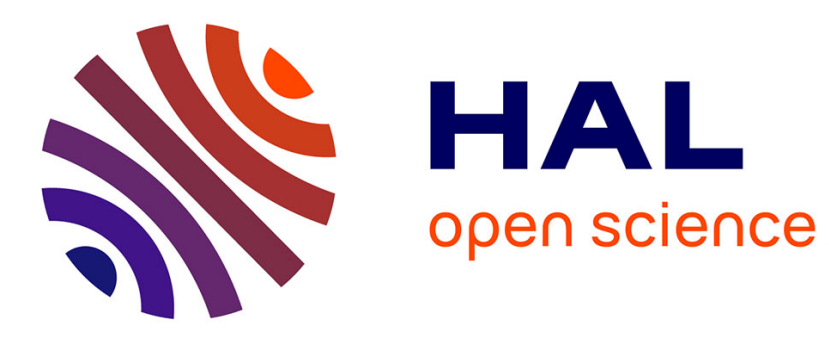

\title{
Femtosecond Dynamics of Isolated Phenylcarbenes
}

\author{
B. Noller, L. Poisson, R. Maksimenka, I. Fischer, J.-M. Mestdagh
}

\section{To cite this version:}

B. Noller, L. Poisson, R. Maksimenka, I. Fischer, J.-M. Mestdagh. Femtosecond Dynamics of Isolated Phenylcarbenes. Journal of the American Chemical Society, 2008, 130 (45), pp.14908-14909. 10.1021/ja804133c . hal-00341195

\section{HAL Id: hal-00341195 \\ https://hal.science/hal-00341195}

Submitted on 24 Nov 2008

HAL is a multi-disciplinary open access archive for the deposit and dissemination of scientific research documents, whether they are published or not. The documents may come from teaching and research institutions in France or abroad, or from public or private research centers.
L'archive ouverte pluridisciplinaire HAL, est destinée au dépôt et à la diffusion de documents scientifiques de niveau recherche, publiés ou non, émanant des établissements d'enseignement et de recherche français ou étrangers, des laboratoires publics ou privés. 


\title{
Supporting Information (6 pages)
}

\section{Femtosecond Dynamics of isolated Arylcarbenes}

\author{
Bastian Noller ${ }^{\dagger, \star}$, Lionel Poisson ${ }^{\dagger}$, Raman Maksimenka $^{\dagger}$, Ingo Fischer ${ }^{\star}$, Jean-Michel \\ Mestdagh $^{\dagger}$ \\ ${ }^{\dagger}$ Laboratoire de Chimie-Physique, Université Paris-Sud, Bât 349, F-91405 Orsay \\ Cedex, France, and Laboratoire Francis Perrin, CEA/DSM/DRECAM/SPAM-CNRS \\ URA 2453, DSM CEA Saclay, F-91191 Gif-sur-Yvette Cedex, France \\ *University of Würzburg, Institute of Physical Chemistry, Am Hubland, D-97074 \\ Würzburg, Germany. \\ e-mail: jmm @ dsm-mail.cea.fr, ingo @ phys-chemie.uni-wuerzburg.de
}

\section{a) Experimental Details}

The experiments were performed in a standard molecular beam apparatus. A cold beam of arylcarbenes was prepared by supersonic jet flash pyrolysis ${ }^{1}$ of diazirines (3-phenyl-3(trifluoromethyl)diazirine (TFPC) and 3-phenyl-3-chlorodiazirine (CPC)), synthesized according to the literature., ${ }^{2,3}$ The precursor was seeded in 3 bars of argon and expanded through a short, weakly heated $\mathrm{SiC}$ tube attached to a water cooled solenoid pulsed valve operating at $20 \mathrm{~Hz}$. The pressure of the source chamber lay at $2 \times 10^{-5} \mathrm{mbar}$. After passing a $1-\mathrm{mm}$ skimmer, the molecular beam reached the detection chamber $\left(2 \times 10^{-7} \mathrm{mbar}\right)$, which was equipped with a time-of-flight mass spectrometer (TOF-MS) and a velocity map imaging (VMI) spectrometer used for mapping ion or electron kinetic energy distributions. Photoelectron images were processed by the pBASEX algorithm. ${ }^{4}$

A $20 \mathrm{~Hz}$ femtosecond Ti:Sa oscillator/amplifier chain was utilized for the experiments. In accordance with the absorption spectra of the carbenes, the third harmonic of the Ti:Sa laser $(265 \mathrm{~nm}, 2 \mu \mathrm{J})$ was used as the pump pulse. Following the initial excitation, the fundamental of the Ti:Sa $(795 \mathrm{~nm}, 480 \mu \mathrm{J})$ was used as the probe pulse in a multiphoton ionization process. Both laser beams were horizontally polarized. The pump-probe time delay was controlled by means of a delay line set on the pump beam and actuated by a computer-controlled stepper motor. The time intervals between two data points were not constant in a given time scan and adjusted to the slope of the decay signal. Around zero in time, data points were taken typically every $8 \mathrm{fs}$, whereas at early and late delay times, longer intervals were chosen. The beams were overlapped in a small angle and sent into the interaction region by a $700 \mathrm{~mm}$ lens for the $265 \mathrm{~nm}$ and a $500 \mathrm{~mm}$ lens for the $795 \mathrm{~nm}$. The $795 \mathrm{~nm}$ were focused $5 \mathrm{~cm}$ away from the interaction region, the focus for the $265 \mathrm{~nm}$ was $14 \mathrm{~cm}$ away. For pump-probe contrast optimization the probe beam was attenuated by a polarizer until the one-color background signal was minimized. The laser cross correlation was typically around $100 \mathrm{fs}$. In the time-delay scans, 256 shots were averaged per data point. The time-resolved spectra reported here typically constitute an average of five such scans.

\section{b) Time of flight mass spectra/pyrolysis on}

In experiments on reactive intermediates it is important to ensure a clean generation of the species of interest. Therefore time-of-flight mass spectra were recorded in order to optimize carbene generation. Spectra of TFPC and CPC with the pyrolysis turned on are presented in figure S1. Only a very small 
carbene signal is present without turning the pyrolysis on, originating from dissociative photoionization of the precursor. These carbene ions are distinguishable from the pyrolytically generated carbenes by velocity map imaging ${ }^{4}$ due to a higher velocity spread. With pyrolysis off the ion signal intensites of $\mathrm{CPC}^{+}$and TFPC ${ }^{+}$are only $0.1-1 \%$ of the intensity obtained with the pyrolysis turned on. In the CPC experiments a side product due to $\mathrm{Cl}$ loss in the pyrolysis is observed in small concentration.

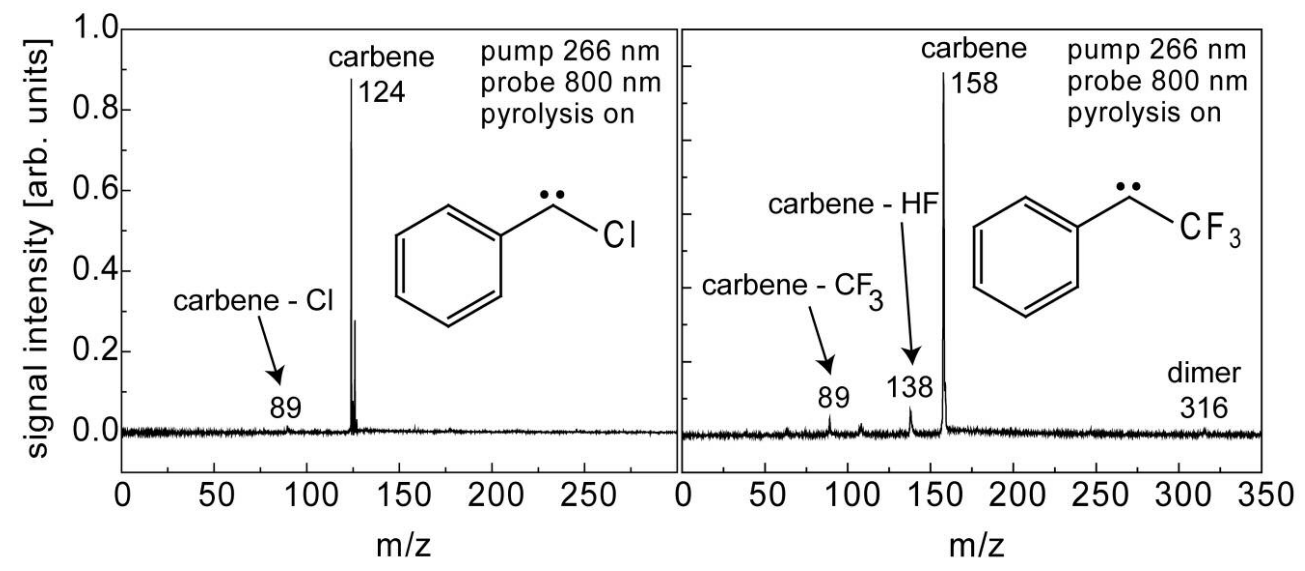

Figure S1. TOF-MS of chlorophenylcarbene (left) and trifluoromethylphenylcarbene (right) generated by jet flash pyrolysis of the corresponding diaziridine. Loss of chlorine is a side reaction in the pyrolytic generation of chlorophenylcarbene, while trifluoromethylphenylcarbene loses $\mathrm{HF}$ and $\mathrm{CF}_{3}$ in a dissociative photoionisation.

Diazirines pyrolise efficiently already at very low pyrolysis temperatures and are volatile enough to use high backing pressures, ensuring a cold molecular beam and fast expansion. When turning the pyrolysis on, the carbene signal strongly increases and the precursor is converted completely.

\section{c) Time-resolved photoelectron spectra}

Time-resolved photoelectron spectra of CPC yield additional insight into the excited-state dynamics. On the left hand side of figure S2 the photoelectron signal at high kinetic energy (for example $0.45 \mathrm{eV}$ $0.58 \mathrm{eV})$ is compared to the signal of near-threshold electrons (0.00-0.04 eV kinetic energy). Both time dependent signals are normalized to the same maximum intensity. Photoelectrons with a kinetic energy of around $0.5 \mathrm{eV}$ (open circles) show the same time dependence as the CPC ion signal given in figure 1 of the paper. The time dependent signal can be perfectly described by two time constants (model: $|\rightarrow| I \rightarrow I I)$ as indicated by a blue solid line $\left(\tau_{1}=40 \mathrm{fs}, \tau_{2}=350 \mathrm{fs}\right)$. On the other hand the low kinetic energy electrons $(0.00-0.04 \mathrm{eV})$ cannot be adequately described by the same two time constants (red line). The time dependent signal of the low kinetic energy electrons has to be described by a three-step decay process $(I \rightarrow I \rightarrow I I I I V)$ as depicted on the right hand side of figure S2. An additional time constant of $\approx 1 \mathrm{ps}$ has to be included in the fit, although the amplitude is rather small. Note that several scans were recorded over a longer range of pump-probe delays, confirming the existence of this additional time constant. However, due to the larger step size, the fast time constant cannot be represented well in these measurements. 

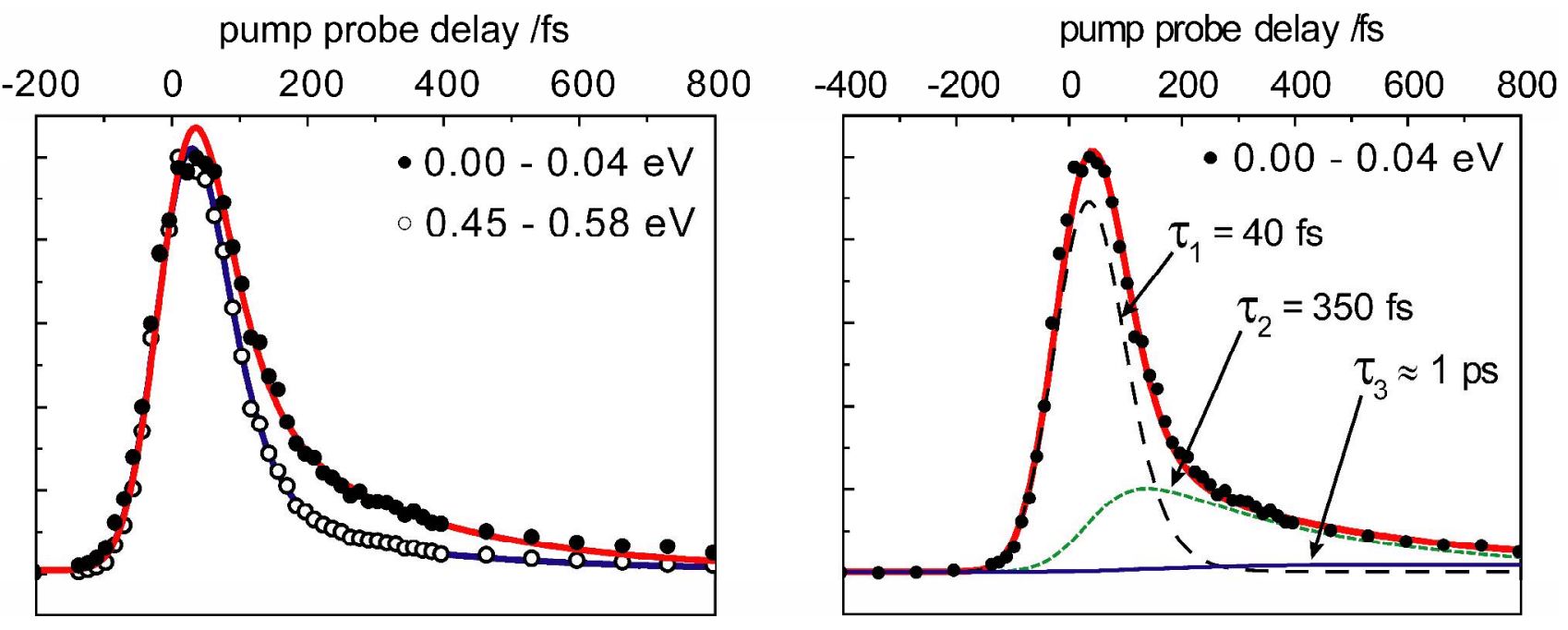

Figure S2. Time delay scans of chlorophenylcarbene recorded by TRPES. Electrons with very low kinetic energy show a different time dependence than electrons around $0.5 \mathrm{eV}$ (left). For an adequate description of the time dependence of electrons with $0.00-0.04 \mathrm{eV}$ three time constants are required. Their contributions to the total signal are given on the right hand side.

\section{d) Possible Isomerization to chlorocycloheptatetraene in the pyrolysis}

The mass spectra given in figure $\mathrm{S} 1$ show a complete conversion of the precursor. However, mass spectrometry cannot easily distinguish between isomers of the same mass. We therefore carried out $a b$ initio calculations of the reaction between chlorophenylcarbene and chlorocycloheptatetraene. The BMK functional and a $6-311^{++} G^{* *}$ basis set were employed in the calculations. ${ }^{5}$ They predict the chlorophenylcarbene to be $70 \mathrm{~kJ} / \mathrm{mol}$ lower in energy than the corresponding chlorocycloheptatetraene The barrier for the isomerization to chlorocycloheptatetraene was calculated by QST3/BMK $/ 6-311^{++} \mathrm{G}^{* *}$ to lie at $96 \mathrm{~kJ} / \mathrm{mol}$ (compare figure 3). Thus the pyrolysis will produce CPC and isomerization to chlorocycloheptatetraene can be ruled out on thermochemical grounds. 


\section{e) Supporting Calculations}

- Isomerization to cycloheptatetraene (BMK/6-311 $\left.{ }^{++} \mathrm{G}^{* *} \mathrm{QST} 3\right)$ : The calculations depicted in figure $\mathrm{S} 3$ were performed using Gaussian $03 .{ }^{6}$

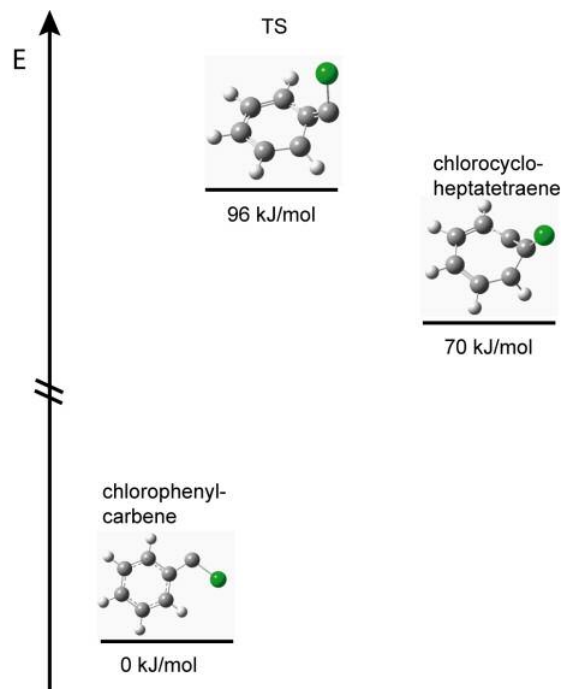

Figure S3. Isomerization of chlorophenylcarbene to chlorocycloheptatetraene as a possible side reaction in the pyrolysis. The $B M K / 6-311++G^{* *}$ calculation shows that the carbene is thermodynamically favored.

-chlorophenylcarbene geometry (0 imaginary frequencies)

(Sum of electronic and zero-point energies $=-729.505469$ ha, $E(R B M K+H F-B M K)=-729.600772678$ ha $)$ :

\begin{tabular}{ccccccc} 
Center & \multicolumn{2}{c}{ Atomic } & \multicolumn{2}{c}{ Atomic } & \multicolumn{3}{c}{ Coordinates } \\
Number & Number & Type & X & $Y$ & Z \\
\hline 1 & 6 & 0 & -1.404516 & -0.992205 & 0.000000 \\
2 & 6 & 0 & -0.084563 & -0.370632 & 0.000000 \\
3 & 6 & 0 & 0.247327 & 1.007917 & 0.000000 \\
4 & 6 & 0 & 0.962138 & -1.322371 & 0.000001 \\
5 & 6 & 0 & 1.575063 & 1.406104 & 0.000000 \\
6 & 1 & 0 & -0.546506 & 1.747072 & -0.000001 \\
7 & 6 & 0 & 2.295590 & -0.919220 & 0.000002 \\
8 & 1 & 0 & 0.689998 & -2.373307 & 0.000001 \\
9 & 6 & 0 & 2.598203 & 0.443684 & 0.000001 \\
10 & 1 & 0 & 1.828126 & 2.461575 & 0.000000 \\
11 & 1 & 0 & 3.092695 & -1.655500 & 0.000003 \\
12 & 1 & 0 & 3.635498 & 0.766287 & 0.000002 \\
13 & 17 & 0 & -2.696192 & 0.207895 & -0.000002
\end{tabular}

-TS geometry (1 imaginary frequency)

(Sum of electronic and zero-point energies=-729.469084 ha, $E(R B M K+H F-B M K)=-729.562845316$ ha):

\begin{tabular}{|c|c|c|c|c|c|}
\hline \multirow{2}{*}{$\begin{array}{l}\text { Center } \\
\text { Number }\end{array}$} & \multirow{2}{*}{$\begin{array}{l}\text { Atomic } \\
\text { Number }\end{array}$} & \multirow{2}{*}{\multicolumn{2}{|c|}{$\begin{array}{l}\text { Atomic } \\
r \quad \text { Type }\end{array}$}} & \multicolumn{2}{|c|}{ Coordinates (Angstroms) } \\
\hline & & & & $X$ & Z \\
\hline 1 & 6 & 0 & -1198674 & -0.527427 & 0663181 \\
\hline 2 & 6 & 0 & -0.051752 & 0.117972 & 0.949928 \\
\hline 3 & 6 & 0 & 0.665862 & 1.314884 & 0.660023 \\
\hline 4 & 6 & 0 & 0.432013 & -1.226395 & 0.619063 \\
\hline 5 & 6 & 0 & 1.739646 & 1.191617 & -0.175677 \\
\hline 6 & 1 & 0 & 0.317834 & 2.276787 & 1.020386 \\
\hline 7 & 6 & 0 & 1.494554 & -1.248746 & -0.364111 \\
\hline 8 & 1 & 0 & 0.280909 & -2.092064 & 1.247603 \\
\hline 9 & 6 & 0 & 2.104266 & -0.083332 & -0.740037 \\
\hline 10 & 1 & 0 & 2.298612 & 2.073304 & -0.473349 \\
\hline 11 & 1 & 0 & 1.871594 & -2.203502 & -0.718761 \\
\hline 12 & 1 & 0 & 2.932054 & -0.114935 & -1.442317 \\
\hline 13 & 17 & 0 & -2.283323 & 0.166410 & -0.547517 \\
\hline
\end{tabular}


-chlorocycloheptatetraene geometry ( 0 imaginary frequencies):

(Sum of electronic and zero-point energies $=-729.478941 \mathrm{ha}, E(\mathrm{RBMK}+\mathrm{HF}-\mathrm{BMK})=-729.572858980)$

\begin{tabular}{|c|c|c|c|c|c|}
\hline \multirow{2}{*}{$\begin{array}{l}\text { Center } \\
\text { Number }\end{array}$} & \multirow{2}{*}{$\begin{array}{l}\text { Atomic } \\
\text { Number }\end{array}$} & \multirow{2}{*}{\multicolumn{2}{|c|}{$\begin{array}{l}\text { Atomic } \\
\text { Type }\end{array}$}} & \multicolumn{2}{|c|}{ Coordinates (Angstroms) } \\
\hline & & & & $X \quad Y$ & Z \\
\hline 1 & 6 & 0 & 0.943721 & -0.091506 & 0.441886 \\
\hline 2 & 6 & 0 & -0.094470 & -0.812987 & 0.675040 \\
\hline 3 & 6 & 0 & -1.280019 & -1.477496 & 0.268065 \\
\hline 4 & 6 & 0 & -0.046261 & 0.878130 & 0.955062 \\
\hline 5 & 6 & 0 & -2.110743 & -0.695202 & -0.483576 \\
\hline 6 & 1 & 0 & -1.513401 & -2.498570 & 0.547905 \\
\hline 7 & 6 & 0 & -1.020621 & 1.480326 & 0.050364 \\
\hline 8 & 1 & 0 & 0.075102 & 1.291520 & 1.956484 \\
\hline 9 & 6 & 0 & -1.902498 & 0.724629 & -0.675821 \\
\hline 10 & 1 & 0 & -3.013633 & -1.131661 & -0.901675 \\
\hline 11 & 1 & 0 & -1.141217 & 2.562564 & 0.050245 \\
\hline 12 & 1 & 0 & -2.610882 & 1.240234 & -1.317799 \\
\hline 13 & 17 & 0 & 2.427610 & -0.088203 & -0.454193 \\
\hline
\end{tabular}

-Frequencies:

\begin{tabular}{|c|c|c|}
\hline Chlorophenylcarbene $/ \mathrm{cm}^{\wedge}-1$ & $\mathrm{TS} / \mathrm{cm}^{\wedge}-1$ & Chlorocycloheptatetraene $/ \mathrm{cm}^{\wedge}-1$ \\
\hline $\begin{array}{c}3226.4074 \\
3212.2277 \\
3196.6141 \\
3191.8318 \\
3177.4613 \\
1632.3916 \\
1608.8926 \\
1517.8512 \\
1475.3693 \\
1361.5434 \\
1318.5636 \\
1245.9320 \\
1212.9796 \\
1187.2687 \\
1117.3313 \\
1049.5643 \\
1046.5098 \\
1028.6125 \\
1013.1943 \\
998.3992 \\
880.2685 \\
864.0732 \\
801.0322 \\
768.7281 \\
700.2308 \\
622.3488 \\
578.3365 \\
474.7507 \\
418.3432 \\
366.7660 \\
231.3948 \\
227.2076 \\
80.8381\end{array}$ & $\begin{array}{c}3243.4171 \\
3206.4929 \\
3198.0930 \\
3182.8376 \\
3173.8902 \\
1666.2013 \\
1606.8142 \\
1511.0969 \\
1460.4194 \\
1393.5736 \\
1326.3234 \\
1204.0342 \\
1194.3534 \\
1161.2866 \\
1097.1483 \\
1019.0415 \\
1004.2947 \\
985.5583 \\
960.8760 \\
932.6661 \\
855.2237 \\
811.8191 \\
785.1409 \\
741.0920 \\
679.0151 \\
601.6772 \\
573.3659 \\
526.7536 \\
410.0179 \\
333.6351 \\
214.6778 \\
95.5648 \\
i 253.0524\end{array}$ & $\begin{array}{c}3204.5982 \\
3192.4558 \\
3175.7357 \\
3154.3745 \\
3115.9624 \\
1904.6359 \\
1618.2017 \\
1512.8292 \\
1458.8125 \\
1402.9794 \\
1342.9985 \\
1236.1164 \\
1205.7272 \\
1170.6591 \\
1054.2456 \\
1018.6357 \\
1001.9691 \\
968.3020 \\
957.2299 \\
930.4177 \\
894.6083 \\
821.0715 \\
736.8720 \\
664.2535 \\
634.5080 \\
619.6414 \\
518.9159 \\
454.7251 \\
432.1202 \\
372.7983 \\
190.6958 \\
165.1988 \\
93.0772\end{array}$ \\
\hline
\end{tabular}

\section{- Time-dependent DFT calculations:}

Calculations of the excited state characteristics and the vertical excitation energies were performed by time-dependent density functional theory (TD-DFT) as implemented in Gaussian 03. A full optimization for the ground state equilibrium geometry was carried out at the B3LYP/6-311 $1^{++} G^{* *}$ level of theory in $C_{s}$ symmetry: 
-chlorophenylcarbene geometry (0 imaginary frequencies)

(Sum of electronic and zero-point Energies $=-729.846555$ ha, $E(R B+H F-L Y P)=-729.941030184$ ha):

\begin{tabular}{cccccc} 
Center & \multicolumn{2}{c}{ Atomic } & \multicolumn{2}{c}{ Atomic } & \multicolumn{3}{c}{ Coordinates $($ Angstroms) } \\
Number & Number & Type & $X$ & $Y$ & $Z$ \\
\hdashline 1 & 6 & 0 & 1.40312 & -0.98179 & 0.000000 \\
2 & 6 & 0 & 0.08606 & -0.37027 & 0.000000 \\
3 & 6 & 0 & -0.24979 & 1.00512 & 0.000000 \\
4 & 6 & 0 & -0.9609 & -1.31998 & 0.000000 \\
5 & 6 & 0 & -1.57533 & 1.40226 & 0.000000 \\
6 & 1 & 0 & 0.54136 & 1.74435 & 0.000000 \\
7 & 6 & 0 & -2.29127 & -0.91814 & 0.000000 \\
8 & 1 & 0 & -0.689 & -2.36883 & 0.000000 \\
9 & 6 & 0 & -2.59589 & 0.44195 & 0.000000 \\
10 & 1 & 0 & -1.82804 & 2.45646 & 0.000000 \\
11 & 1 & 0 & -3.08576 & -1.655 & 0.000000 \\
12 & 1 & 0 & -3.63217 & 0.76239 & 0.000000 \\
13 & 17 & 0 & 2.69398 & 0.20622 & 0.000000
\end{tabular}

This geometry was used in the TD-B3P86/6-311++g* calculations for the excited states:

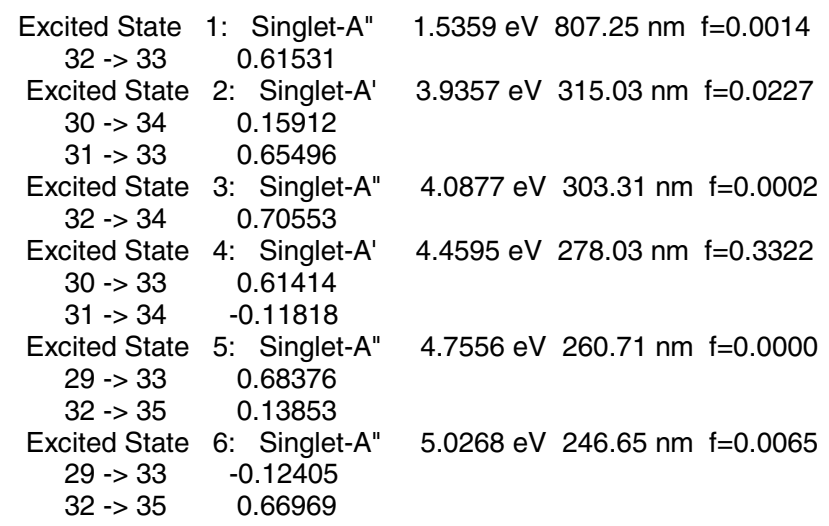

\section{References:}

(1) Kohn, D. W.; Clauberg, H.; Chen, P. Rev. Sci. Instrum. 1992, 63, 4003-4005.

(2) Graham, W. H. J. Am. Chem. Soc. 1965, 87, 4396.

(3) Brunner, J.; Senn, H.; Richards, F. M. J. Biol. Chem. 1980, 255, 3313.

(4) Whitaker, B. Imaging in Molecular Dynamics; Cambridge University Press: Cambridge, 2003.

(5) Boese, A. D.; Martin, J. M. L. J. Chem. Phys. 2004, 121, 3405.

(6) Frisch, M. J.; Trucks, G. W.; Schlegel, H. B.; Scuseria, G. E.; Robb, M. A.; Cheeseman, J. R.; Jr., J. A. M.; Vreven, T.; Kudin, K. N.; Burant, J. C.; Millam, J. M.; Iyengar, S. S.; Tomasi, J.; Barone, V.; Mennucci, B.; Cossi, M.; Scalmani, G.; Rega, N.; Petersson, G. A.; Nakatsuji, H.; Hada, M.; Ehara, M.; Toyota, K.; Fukuda, R.; Hasegawa, J.; Ishida, M.; Nakajima, T.; Honda, Y.; Kitao, O.; Nakai, H.; Klene, M.; Li, X.; Knox, J. E.; Hratchian, H. P.; Cross, J. B.; Bakken, V.; Adamo, C.; Jaramillo, J.; Gomperts, R.; Stratmann, R. E.; Yazyev, O.; Austin, A. J.; Cammi, R.; Pomelli, C.; Ochterski, J. W.; Ayala, P. Y.; Morokuma, K.; Voth, G. A.; Salvador, P.; Dannenberg, J. J.; Zakrzewski, V. G.; Dapprich, S.; Daniels, A. D.; Strain, M. C.; Farkas, O.; Malick, D. K.; Rabuck, A. D.; Raghavachari, K.; Foresman, J. B.; Ortiz, J. V.; Cui, Q.; Baboul, A. G.; Clifford, S.; Cioslowski, J.; Stefanov, B. B.; Liu, G.; Liashenko, A.; Piskorz, P.; Komaromi, I.; Martin, R. L.; Fox, D. J.; Keith, T.; Al-Laham, M. A.; Peng, C. Y.; Nanayakkara, A.; Challacombe, M.; Gill, P. M. W.; Johnson, B.; Chen, W.; Wong, M. W.; Gonzalez, C.; Pople, J. A. Gaussian 03, Revision C.02, 2004. 